Kristin L. Woods, ${ }^{1}$ Laura Acuña-Maldonado, ${ }^{2}$ Donna P. Clements, ${ }^{2}$ Connie L. Fisk, ${ }^{2}$ Donald M. Stoeckel, ${ }^{2}$ Gretchen L. Wall ${ }^{2}$ and Elizabeth A. Bihn²*

${ }^{1}$ Alabama Cooperative Extension System, Auburn University, 120 Court Street, Grove Hill, AL 36451, USA

2Produce Safety Alliance, Dept. of Food Science, Food Research Laboratory, Cornell University, 665 West North St., Geneva, NY 14456, USA
PEER-REVIEWED ARTICLE

Food Protection Trends, Vol 40, No. 6, p. 435-449 Copyright ${ }^{\oplus} 2020$, International Association for Food Protection 2900 100th Street, Suite 309, Des Moines, IA 50322-3855

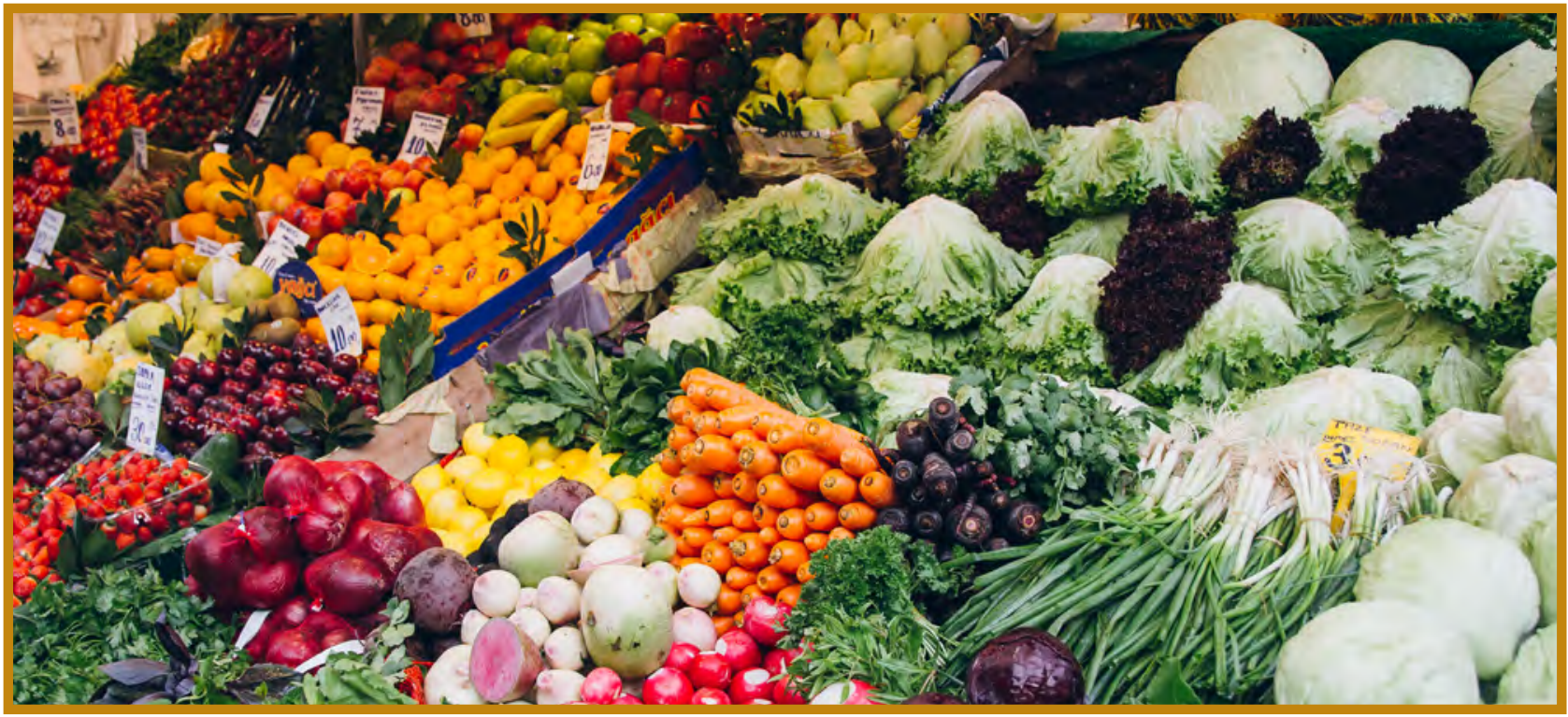

\title{
Produce Safety Alliance Train-the-Trainer Course: Developing Trainers to Support Fruit and Vegetable Growers
}

\section{ABSTRACT}

In 2010, the Produce Safety Alliance (PSA) entered

into a cooperative agreement with the U.S. Department of Agriculture with funding from the U.S. Food and Drug Administration to develop a standardized curriculum and nationwide educational outreach program for growers to support understanding and implementation of the Food Safety Modernization Act (FSMA) Produce Safety Rule (PSR). To meet the national training need, the PSA established a Train-the-Trainer program to develop a cadre of qualified PSA Trainers and Lead Trainers to teach the PSA Grower Training Course. The training program officially launched in September 2016. The 2-day PSA Train-the-Trainer Course consists of the PSA Grower Training Course that includes seven modules that integrate good agricultural practices and the PSR requirements plus additional content to help prepare PSA Trainers to teach the material. PSA Train-the-Trainer Course participants were asked to complete a course evaluation to assess the quality of the curriculum and the adequacy of the training program for preparing them to deliver PSA
Grower Training Courses. Information from the evaluations has been used to create additional resources to support growers and PSA Trainers.

\section{INTRODUCTION}

Over the last few decades, the Centers for Disease Control and Prevention has reported that produce is associated with a significant number of foodborne illnesses in the United States; $46 \%$ of foodborne illnesses from 1998 to 2008 were traced back to produce with the single highest number of illnesses attributed to leafy greens (7). More recent data confirm that this trend continues, and contaminated produce has been identified as a source of foodborne illness from Salmonella, Escherichia coli O157:H7, Listeria monocytogenes, and Campylobacter $(1,5)$. In 1999, the U.S. Food and Drug Administration (FDA) (17) issued a voluntary guidance document to help reduce the incidence of foodborne illnesses attributed to produce. This guidance established good agricultural practices (GAPs) for produce growers, and these GAPs have become the basis for many buyer-required food safety audits. Despite the incorpora- 
tion of food safety practices into audits, foodborne illness outbreaks attributed to produce continued to occur, leading to the passage of the Food Safety Modernization Act (FSMA) in 2011 (7). The FSMA was signed into law with the intent of putting measures into place that would take a preventive approach to reducing the incidence of foodborne illness outbreaks in the United States. The FSMA contains many rules and outlines mandatory food safety regulations for growers. With this new regulation, the FDA recognized the need for education and training support for the fruit and vegetable industry to help producers understand and implement practices required by the regulation. Cornell University, home to the National GAPs Program since 1999, formed the Produce Safety Alliance (PSA) via a cooperative agreement between Cornell University, the U.S. Department of Agriculture (USDA), and the FDA to develop a standardized curriculum and nationwide educational outreach program for growers.

In 2010, the PSA began developing a standardized national training program and outreach plan to meet the overarching goal of providing the produce industry and associated groups with training and educational opportunities related to GAPs and the regulatory requirements set forth by the FSMA Produce Safety Rule (PSR) (19). In addition to the practices required within the PSR, it contains an educational requirement in $\$ 112.22$ (c), which states that "At least one supervisor or responsible party for your farm must have successfully completed food safety training at least equivalent to that received under standardized curriculum recognized as adequate by the FDA" (19). This educational requirement is intended to familiarize growers and farm supervisors with the PSR requirements and with the GAPs that support regulatory compliance.

In 2013, the FDA estimated that of the 121,116 total produce farms in the United States, 35,029 would be covered by the PSR (18). The remaining farms would be exempt from the regulation because they fall under the small farm exclusion, are qualified exempt based on food sales and market channel, grow only crops that are rarely consumed raw, or grow only crops that are designated for commercial processing (18). However, the farms that fall under an exclusion or exemption may be pressured to implement PSR requirements by their buyers (19). To meet the national training need, the PSA established a Train-theTrainer program that would develop a cadre of qualified PSA Trainers and Lead Trainers to teach the PSA Grower Training Course. Once a participant has attended the 2-day PSA Train-the-Trainer Course, they are a PSA Trainer and are eligible to apply to be a PSA Lead Trainer. These processes are designed to develop trainers who will be able to effectively and consistently deliver the PSA Grower Training Course and respond to grower questions during the training, so that course participants are well informed and prepared to implement FSMA PSR requirements (12).
This article contains an outline of the curriculum development process, presents evaluation results from the national rollout of the PSA Train-the-Trainer Course, describes the feedback received as the program was launched, and explains how the information gained from course evaluations was used to address outreach needs. This article further describes actions taken by the PSA to nimbly respond to feedback and meet the needs of trainers as they begin delivering the PSA Grower Training Course across the country.

\section{MATERIALS AND METHODS \\ PSA Grower Training Curriculum development}

As a first step in the development process, a GAPs Education and Training Materials Conference was hosted in Orlando, FL on 29 and 30 June 2011. The conference was attended by 125 individuals from academia, industry, and regulatory agencies from 28 U.S. states and Spain (9). The goal of the conference was to review existing outreach materials in an effort to avoid duplicating materials that already existed. An Educational Materials Showcase held during the conference allowed for the sharing of materials and discussions between participants, including those interested in the materials and those who had developed them. A recurring theme at the conference was that food safety standards should not vary, but how the practices are implemented might vary depending on farm size, location, commodities grown, and other farm-specific attributes. The PSA also shared how it was working to identify challenges to understanding and implementing GAPs on small and very small farms through the development of 10 working committees that had started to meet. These efforts were key to developing the new PSA Grower Training Curriculum. Meeting participants were encouraged to join the working committees and to collaborate with the PSA as it moved forward. Between May 2011 and April 2012, 178 individuals participated on 10 working committees, and on average each individual served on 3 committees (Fig. 1). These committees collectively met 72 times to discuss challenges related to food safety understanding and implementation in each of the focus areas. Each committee also developed recommendations to the Executive Committee, including critical concepts that would be used to guide curriculum content development, learning objectives, and areas key to developing competent trainers (11). Working committee recommendations can be accessed on the PSA Website (https://producesafetyalliance.cornell.edu/alliance/committees/workingcommittee/). Additional grower input on the format and content of the PSA standardized curriculum was gathered via eight nationwide focus groups with 89 unique growers from farms of various sizes that engaged in diverse farming practices (e.g., organic and conventional) (10). The grower input was incorporated into the curriculum content and development process. Most notably, the growers requested a 


\section{Working Committes Core Concepts}

PSA Curriculum

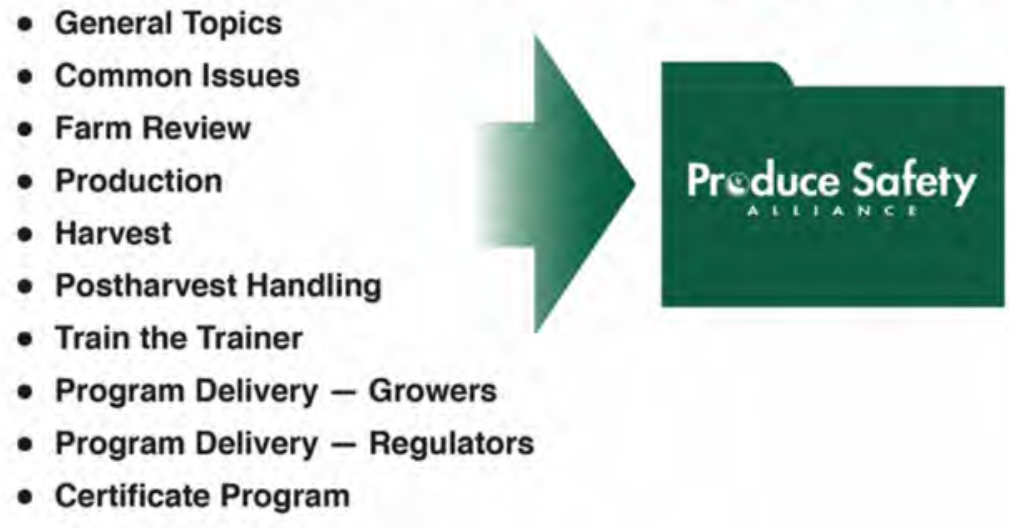

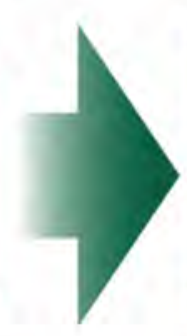

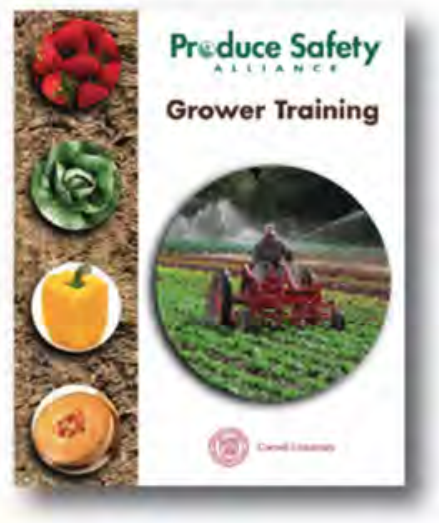

FIGURE 1. PSA Working Committees.

face-to-face course that could be delivered in 1 day from a trustworthy source, such as a cooperative extension educator. Utilizing the proposed PSR requirements published in 2013 and the critical concepts developed by members of the Working Committees, the PSA began content development for the standardized curriculum. The content of the course was evaluated slide by slide by the Steering and Executive Committees with additional input from industry representatives in December 2014 at a face-to-face meeting in Geneva, NY. The PSA Grower Training Course was piloted in Hershey, PA in January 2015. Subsequently, the curriculum was updated in the following ways:

(i) Several slides were removed, modified, and/or made optional based on concerns about the amount of content to be delivered in a 1-day PSA Grower Training Course.

(ii) The regulatory requirements were better defined to address confusion about requirements versus best practices. Use of the words "must" and "should" were reviewed, and the regulatory section symbol $(\$)$ was added to slides that contained regulatory content on the slide or in the notes as a cue to learners that regulatory content was being discussed. A quick regulatory reference table and regulatory citations to teaching notes were also added.

(iii) The decision was made that everyone, both trainers and participants in the PSA Grower Training Course, would receive the same training manual. Teaching notes were expanded to provide more in-depth information for trainers and to ensure that growers can continue to expand their knowledge after the training. Feedback from the pilot course that included owners of large and small farms utilizing a variety of farming practices and representing a range of food safety knowledge and experience indicated that providing more information in the teaching notes could help alleviate concerns that the content was too basic for some growers. Providing growers of all experience levels with the teaching notes and slide references would allow these growers to readily embark in self-directed learning with the material after the training.

Two Train-the-Trainer pilot courses were held in Kalamazoo, Michigan and Harrisburg, Pennsylvania in 2015. Final edits to the standardized curriculum were incorporated after the release of the final FSMA PSR in November 2015. Throughout the curriculum development process, PSA engaged with the FDA Division of Produce Safety staff members to review and edit the curriculum to ensure alignment with the PSR. The training program officially launched in September 2016.

PSA standardized curriculum and course format

The PSA Grower Training Curriculum consists of seven modules that integrate GAPs and the FSMA PSR requirements. After completing all seven modules, a PSA Grower Training Course participant is eligible to receive a certificate from the Association of Food and Drug Officials. The seven modules are:

(i) Module 1: Introduction to Produce Safety

(ii) Module 2: Worker Health, Hygiene, and Training

(iii) Module 3: Soil Amendments

(iv) Module 4: Wildlife, Domesticated Animals, and Land Use

(v) Module 5: Agricultural Water (Part I: Production Water; Part II: Postharvest Water)

(vi) Module 6: Postharvest Handling and Sanitation

(vii) Module 7: How to Develop a Farm Food Safety Plan

The 2-day PSA Train-the-Trainer Course includes the seven modules of the PSA Grower Training Curriculum plus additional content to help prepare PSA trainers to teach the material (Fig. 2). Incorporating the modules of the PSA Grower Training Curriculum into the PSA Train-the-Trainer Course ensures that PSA Trainers are familiar with each topic and how the content relates across 


\section{Preduce Safety}

PSA TRAIN-THE-TRAINER COURSE AGENDA <LOCATION

DAY ONE -
8:30 AM Sign-in and Refreshments
9:00 AM Welcome, Introductions, and Course Expectations
9:30 AM Review of Training Resources - Manuals \& Jump Drives
10:00 AM Review of Key Concepts - Module 1: Introduction to Produce
$\quad$ Safety
11:15 AM Break
11:30 AM Review of Key Concepts - Module 2: Worker Health. Hygiene,
12:30 PM Lunch Provided
1:15 PM Review of Key Concepts - Module 3: Soil Amendments
2:00 PM Break
2:15 PM Review of Key Concepts - Module 4: Wildlife, Domesticated
$\quad$ Animals, \& Land Use
3:00 PM Adult Education, Multi-day Training Options, and Partnerships
4:30 PM PSA Website - Trainer Resources
4:50 PM Day 1 Wrap Up: Things to Add to the Parking Lot and
5:00 PM Adjourn

\section{Preduce Safety}

DAY TWO -
8:30 AM Sign-in and Refreshments
9:00 AM Day One Reflections
9:45 AM Review of Key Concepts - Module 5: Agricultural Water Part 1,
$\quad$ Production Water
10:45 AM Break
11:00 AM Review of Key Concepts - Module 5: Agricultural Water Part 2,
$\quad$ Postharvest Water
11:45 PM Lunch Provided
12:30 AM Review Key Concepts-Module 6: Postharvest Handling and
$\quad$ Sanitation
1:30 PM Review Key Concepts - Module 7: How to Develop a Farm Food
$\quad$ Safety Plan
$\begin{array}{r}\text { 2:15 PM Break } \\ \text { 2:30 PM Break Out Session: Trainer Review of Modules } \\ \text { 4:00 PM PSA Training Protocol, Lead Trainer Application, and Course } \\ \text { 4:30 PM Respond to Anything Remaining in the Parking Lot } \\ \text { 4:45 PM Final Questions, Closing Statements, and Collection of } \\ \quad \text { Adjourn }\end{array}$

FIGURE 2. Example PSA Train-the-Trainer Course agenda.

modules. The additional content includes principles of adult education, how to develop working partnerships for delivering training, delivery modifications, course protocols, PSA expectations of trainers, and course registration information. The PSA Train-the-Trainer Course also includes an interactive group discussion activity during which trainers are asked to identify challenging areas of the curriculum and to discuss these challenges and solutions with their peers. An attendee who completes the 2-day PSA Train-the-Trainer Course is considered a PSA Trainer and is eligible to apply to become a PSA Lead Trainer (12). To teach any module during a PSA Grower Training Course, a trainer must have attended a PSA Train-the-Trainer Course. Each PSA Grower Training Course also must include at least one PSA Lead Trainer. In conjunction with the rollout of the Train-the-Trainer Course, the PSA Lead Trainer process was launched and began accepting PSA Lead Trainer applications in early November 2016. At the Trainthe-Trainer Course rollout, all seven modules were taught the first day of training, and the additional content was taught the second day. This course agenda was gradually adapted over the first few months of use to its current 2-day format, which intersperses discussion, activities, and the trainer-specific modules into the presentation of the core modules. Currently, the first four modules are taught during the first training day followed by the Principles of Adult Education and Multiday Training Options; on the second day of training modules 5 through 7 are covered followed by a breakout session and course logistics. The adjustment in delivery of the course modules was made in response to feedback from training participants who reported that receiving all of the technical information contained in the modules on day 1 was overwhelming and that an agenda modification would result in a more effective experience. The current format allows PSA Trainers to experience the highly technical information over a longer period of time and move some more challenging information, such as that contained in the Agricultural Water module to the morning of the second day.

PSA Train-the-Trainer Course participants receive a PSA Grower Training Manual that includes all seven standardized curriculum module slide sets and teaching notes, the codified language of the FSMA PSR, a FSMA PSR regulatory reference table, a glossary of terms, a section of farm food safety plan writing resources, a list of resources from the FDA, USDA Agricultural Marketing Service, and USDA Natural Resource Conservation Service, and a list of references. PSA Train-the-Trainer 
Course participants also receive a supplemental packet that includes an Adult Education and Multi-day Training Options module and information on course logistics. The standardized curriculum slide sets and teaching notes are identical to those received by participants in the PSA Grower Training Course. This allows trainers to correctly reference page numbers, notes, and references while teaching.

\section{Course evaluation}

Participants in Train-the-Trainer Courses were asked to complete a course evaluation to assess the quality of the curriculum and the adequacy of the training program for meeting the goal of preparing PSA Trainers to deliver PSA Grower Training Courses (Fig. 3). Course evaluations along with instructions were provided at the beginning of each course. Participants were encouraged to complete the evaluation throughout the 2-day course to increase the likelihood that their opinions would be captured in detail. The evaluation instrument consisted of questions to assess self-perceived increases in knowledge, clarity of training content, sufficiency of the information presented, adequacy of the information provided in the PSA Train-the-Trainer

\section{Produce Safety \\ Train-the-Trainer Course Evaluation}
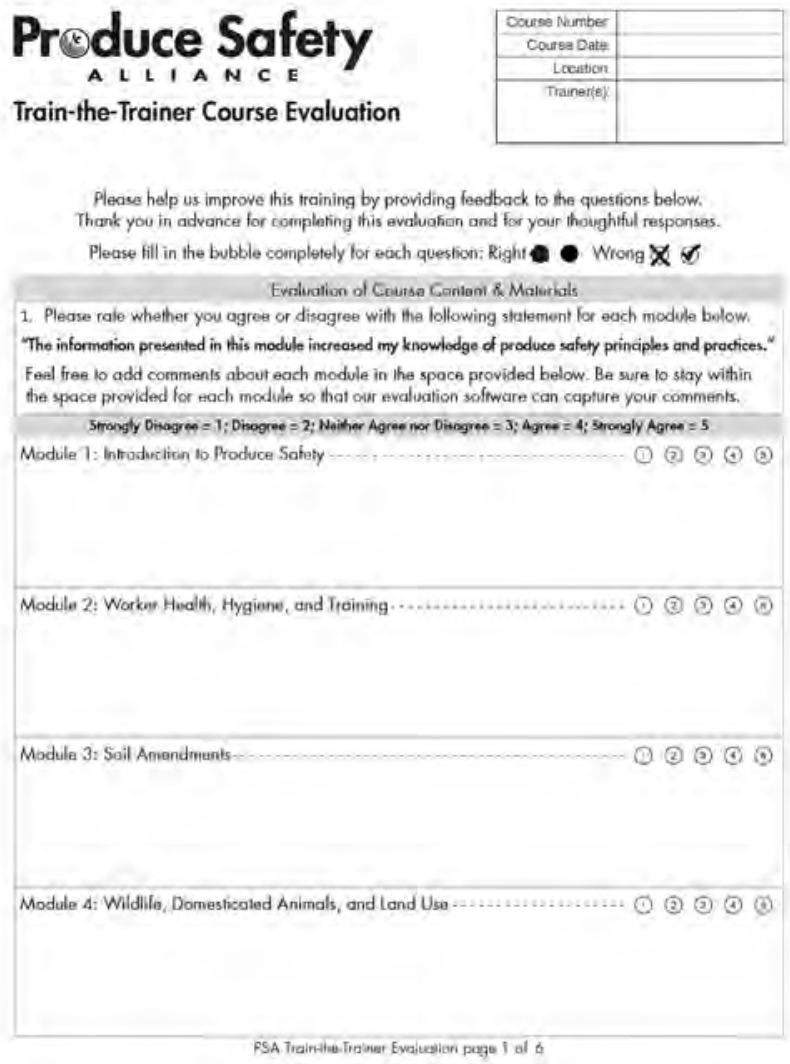

Manual, participant plans to train growers using the PSA Grower Training Curriculum, follow-up assistance that could be provided by the PSA, and optional demographic information (gender, age, occupation, education, and training experience). The goal of the evaluation was to gather a holistic view of the adequacy of both the overall training program and the individual modules within the course. Questions referring to a participant's readiness to teach the material were asked to specifically assess learning at the application level of Bloom's learning theory (2). The PSA did not assess lower levels of learning for this course, such as knowledge and comprehension; however, knowledge change is assessed at some FSMA Regional Centers funded by the FDA and the USDA in cooperative agreements. An initial analysis of pre- and post-test scores indicated a significant increase in knowledge after completion of the PSA Grower Training Course (15). Participants in PSA Train-the-Trainer Courses were also asked to indicate their race or ethnicity; however, the question was presented in a way that may have encouraged participants to choose between their race and ethnicity. Race and ethnicity are reported but should be considered rough estimates because of this confusion. The evaluations

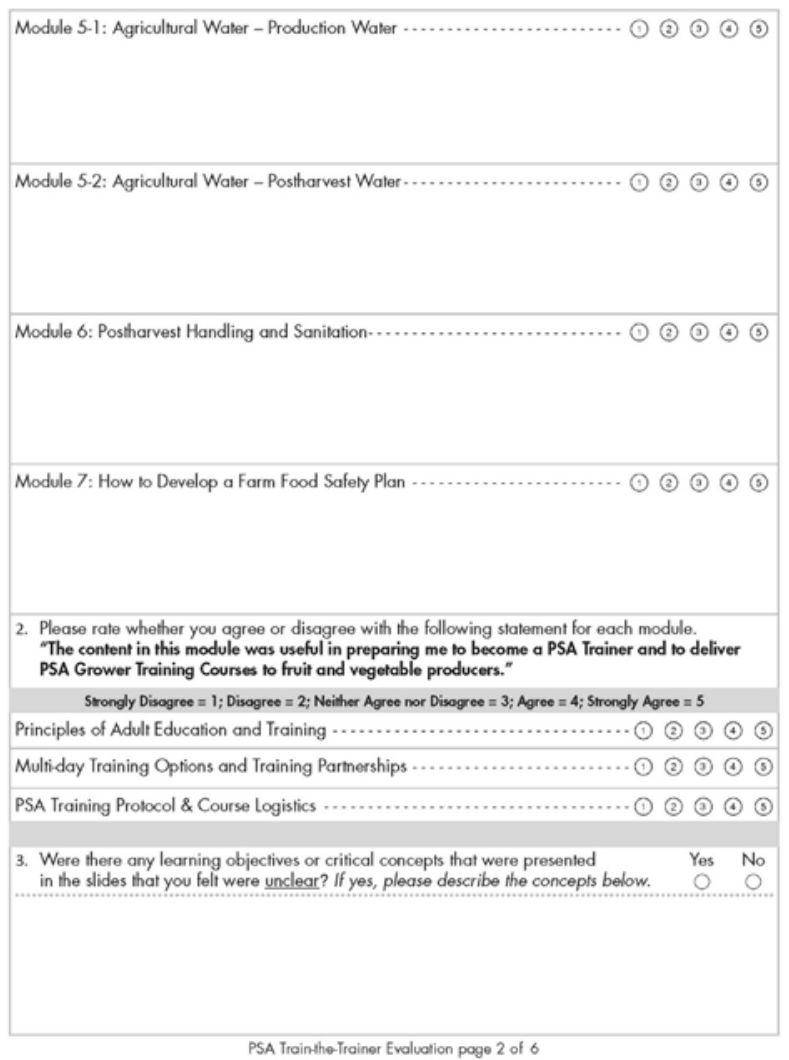




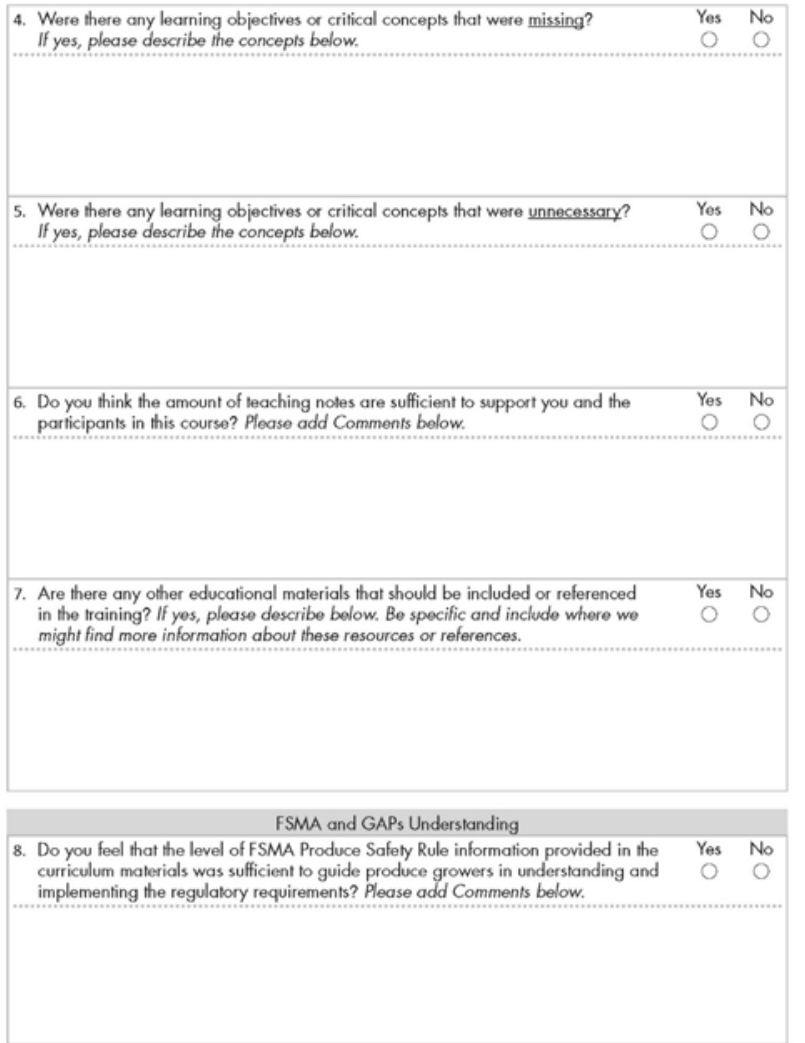

PSA Trointhe-Trainot Evaluation poge 3 of 6

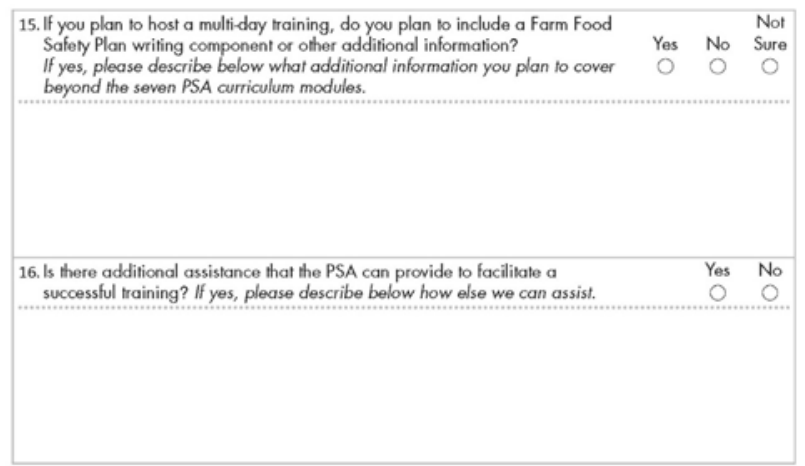

\begin{tabular}{|c|c|}
\hline \multicolumn{2}{|c|}{ Demographics } \\
\hline Gender & Age \\
\hline Male & 15.25 \\
\hline Female & $26-40$ \\
\hline \multirow{3}{*}{ Other } & 0.41 .55 \\
\hline & 56.65 \\
\hline & $066+$ \\
\hline Occupation & Ethnicity \\
\hline Farm owner/operator & White \\
\hline Extension Educalor & Hispanic/Latino \\
\hline Gov't. Employee & Black/African American \\
\hline Produce Industry & Native American/Am. Indian \\
\hline Consultant & Asian/Pacific Islander \\
\hline O Other (please specify below): & O Other (please specify below): \\
\hline & \\
\hline & \\
\hline
\end{tabular}

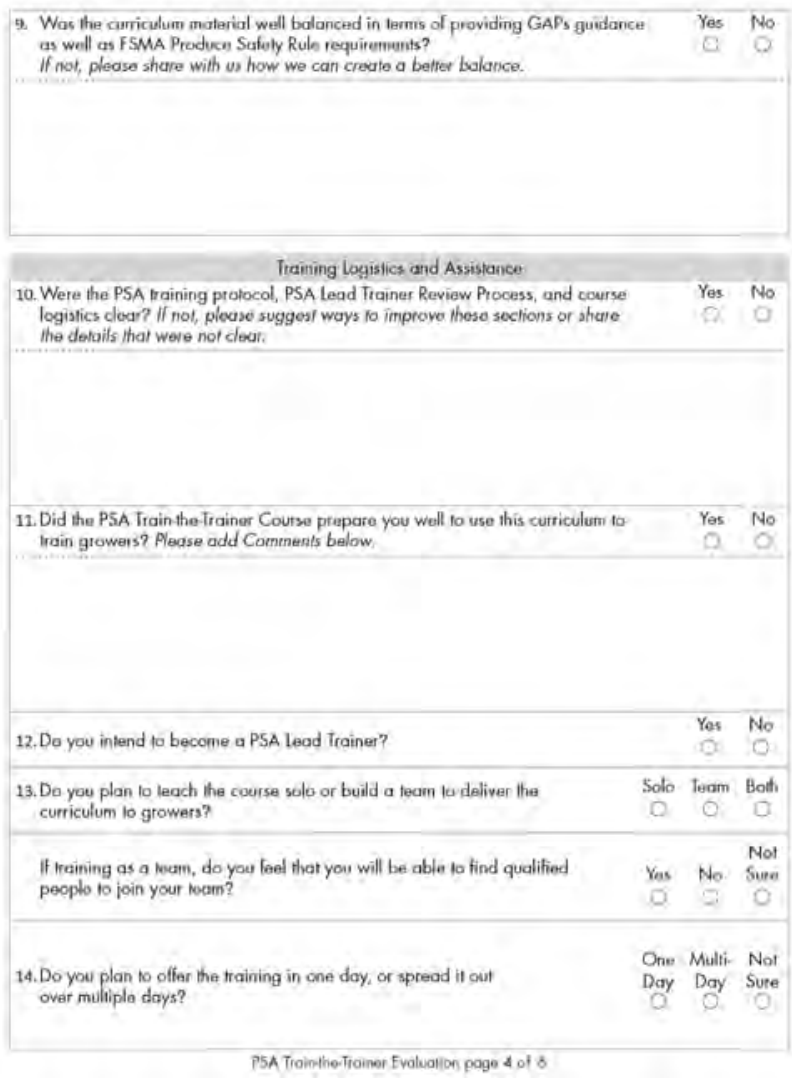

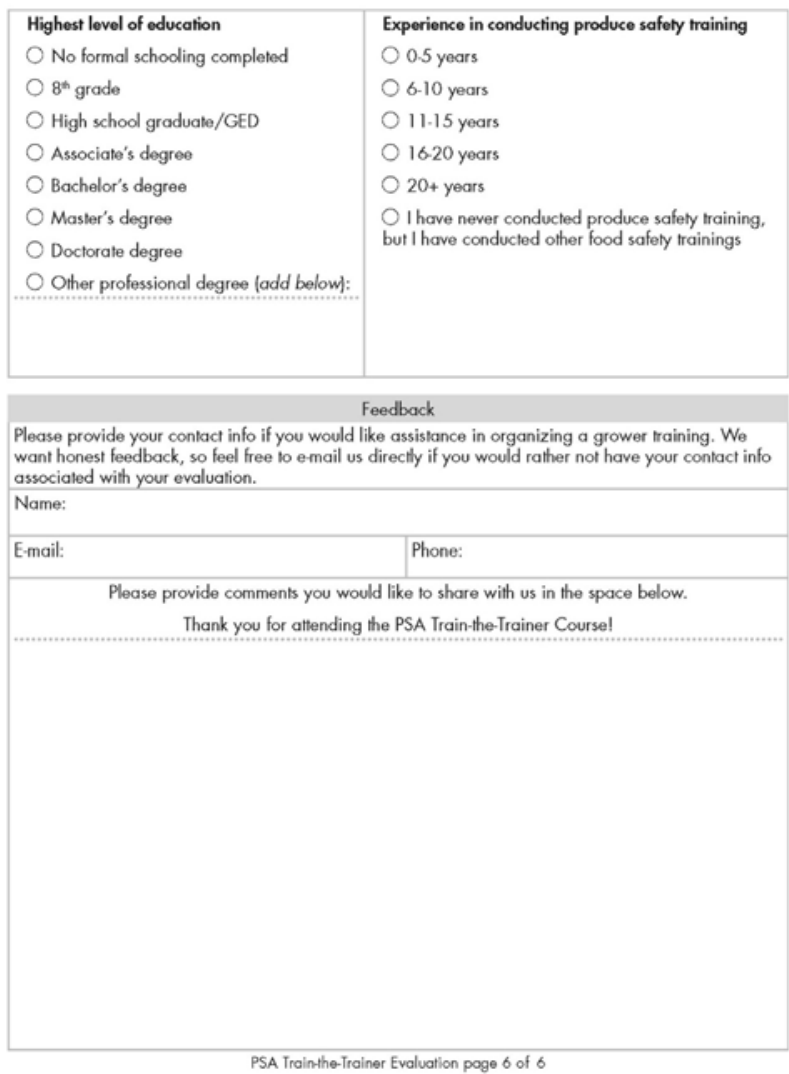

FIGURE 3. PSA Train-the-Trainer Course evaluation instrument. (cont.) 
from 25 PSA Train-the-Trainer Courses hosted in the United States during the first 8 months after the training launched (14 September 2016 to 24 April 2017) are included in the present report.

\section{Statistical analysis}

Evaluation results were collated, and analyses were conducted using SPSS Statistics for Windows 2012 (SPSS, IBM, Armonk, NY). The Pearson chi-square test was used to identify differences in the way demographic groups responded to questions about the sufficiency of the curriculum. Differences identified with the chi-square test were considered significant at $P<0.05$. Adjusted standardized residual examination was used to identify where those differences occurred and in what direction. Adjusted standardized residuals $>2.0$ or $<-2.0$ were considered significant.

The Wald chi-square test was used to approximate the effect of training date on responses to questions about the sufficiency of the curriculum. Estimated marginal means were used to predict participant responses later in the period studied when the Wald chi-square test results revealed an effect of training date on participant responses.

Differences in self-reported knowledge gained among PSA Grower Training modules was assessed using Friedman's test, and differences were considered significant at $P<0.05$. Post hoc analysis was conducted using the Wilcoxon signed-rank test with a conservative Bonferroni adjustment. Because eight groups were assessed pairwise, a $P$-value of $<0.002$ was considered significant (i.e., 0.05 divided by 28). When post hoc analyses were conducted on the PSA Train-the-Trainer modules, the significance level was set at $P<0.017$ because three groups were compared pairwise.

\section{RESULTS AND DISCUSSION Demographics}

Of the 819 participants in PSA Train-the-Trainer Courses held from 14 September 2016 to 24 April 2017, those who responded were predominantly Caucasian and 26 to 65 years of age, with roughly an even split between the genders (Table 1). The largest professional category comprised extension educators (38.1\% of participants), and most participants $(73.9 \%)$ reported having $<10$ years of produce safety training experience (Table 1 ). The relatively few years of experience reported by PSA Trainers is indicative of the emerging field of produce safety education and the impact of the FSMA. Presented over 2 days, the PSA Train-the-Trainer Course benefits participants, especially those with limited produce safety training experience, by allowing more time to discuss the complex training content, ask questions, and identify potential challenges to teaching the content through structured breakout sessions. The PSA has begun working with the FSMA Regional Centers to develop PSA Advanced Trainer Courses that will continue to develop trainers by providing in-depth technical background on specific produce safety topics and instructor tips to increase participant engagement.

\section{Suitability of the PSA Train-the-Trainer Course}

As a national standardized training program, the PSA course content must be suitable for teaching new PSA Trainers how to deliver the PSA Grower Training Course. The majority of participants indicated that the learning objectives and critical concepts were clear, inclusive, and necessary to the training (Table 2). Women were more likely to report that objectives were unclear $\left(\chi^{2}(2, N=702)\right.$ $=8.666, P=0.013)$. Because the evaluation instrument also contained a comment box asking respondents to fill in what they thought was unclear, this gender difference may be related to general differences in survey participation and information seeking. Survey studies have revealed that women are more likely to participate in mail-in and online surveys in general $(8,14)$. Gender differences have been studied extensively in the area of seeking additional healthrelated information but have not focused specifically on food safety information. In general, women are more likely to seek additional health-related information, and these findings may be extrapolated to explain why women would be more likely to indicate when clarification is needed in the PSA Curricula (4). However, these gender differences were not found in other categories of this study. Consultants $\left(\chi^{2}\right.$ $(5, N=742)=11.375, P=0.044)$ and those with master's degrees $\left(\chi^{2}(7, N=740)=16.337, P=0.022\right)$ were more likely to report that objectives or critical concepts were missing. Participants who indicated that components were missing may have considered audit requirements to be critical components of produce safety training. When participants were asked what additional materials the PSA could provide, $13 \%$ (17 of 132 ) specifically requested food safety plan-related resources, even though a food safety plan is not required by the PSR.

One noteworthy modification made to the PSA Grower Training Curriculum after the pilot courses were completed was addition of detailed trainer notes to support the presentation slides. These notes include regulatory requirements, teaching examples, and resources for more information. The same teaching notes are included in the manuals that PSA Trainers and PSA Grower Training Course attendees receive. Most participants (92\%) agreed that the amount of teaching notes was sufficient to support PSA trainers and future participants in the Grower Training Course. Women were more likely to report that the notes were sufficient $\left(\chi^{2}(2, N=762)=6.367, P=0.041\right)$. 


\section{TABLE 1. Participant demographics and produce safety training experience $\left(n=\mathbf{8 1 9}^{\mathrm{a}}\right)$}

\section{Characteristic}

\section{Gender}

\begin{tabular}{c}
\hline Femal \\
\hline Male \\
\hline Other \\
\hline Age $(\mathbf{y r})$ \\
\hline$\geq 66$ \\
\hline $56-65$ \\
\hline $41-55$ \\
\hline $26-40$ \\
\hline $15-25$
\end{tabular}

Race or ethnicity

White

Hispanic, Latino

Asian, Pacific Islander

Black, African American

Native American, American Indian

Other or multiple answers

\section{Education}

No schooling completed

Completed 8th grade

High school graduate, GED

Associate's degree

Bachelor's degree

Master's degree

Doctoral degree

Other professional degree

Occupation

\begin{tabular}{l}
\hline Extension educator \\
\hline Consultant \\
\hline Government employee \\
\hline Produce industry \\
\hline Farm owner, operator \\
\hline Other \\
\hline
\end{tabular}

Produce safety training experience $(\mathrm{yr})$

\begin{tabular}{l|c}
\hline $0-5$ & $55(423)$ \\
\hline $6-10$ & $19(141)$ \\
\hline $11-15$ & $9(65)$ \\
\hline $16-20$ & $4(29)$ \\
\hline$>20$ & $3(23)$ \\
\hline None, but other food safety training experience & $11(83)$ \\
\hline
\end{tabular}

$\%$ (no.) of participants

$47(381)$
$47(389)$
$0.1(1)$

$3(22)$

$18(148)$

$32(263)$

$36(302)$

$5(43)$

$63(517)$

$14(114)$

$6(52)$

$5(42)$

$2(19)$

$3(28)$

$0.1(1)$

$0.4(3)$

$6(50)$

$4(36)$

$31(252)$

$33(270)$

$19(159)$

$2(15)$

$38(312)$

$13(108)$

$12(98)$

$11(91)$

$7(56)$

$14(118)$

$5(423)$

$(141)$

$9(65)$

$4(29)$

$11(83)$

${ }^{a}$ Every participant did not respond to every question. 


\section{TABLE 2. Responses to questions about the suitability of the training program and how}

participant responses changed over time

\begin{tabular}{|c|c|c|c|}
\hline \multirow{2}{*}{ Adequacy of curriculum change over time } & \multicolumn{2}{|c|}{$\%($ no. $)$ of responses } & \multirow{2}{*}{$\begin{array}{c}P \text {-value } \\
\left(\text { Wald } \chi^{2}\right)^{a}\end{array}$} \\
\hline & Yes & No & \\
\hline Were any learning objectives or critical concepts unclear? & $22(160)$ & $78(567)$ & 0.807 \\
\hline Were any learning objectives or critical concepts missing? & $13(103)$ & $87(663)$ & 0.584 \\
\hline Were any learning objectives or critical concepts unnecessary? & $7(50)$ & $94(720)$ & 0.072 \\
\hline Is the amount of teaching notes sufficient to support you and the participants in the course? & $92(725)$ & $8(64)$ & 0.654 \\
\hline $\begin{array}{l}\text { Are there any other educational materials that should be included or referenced in } \\
\text { the training? }\end{array}$ & $35(256)$ & $66(486)$ & $0.007^{*}$ \\
\hline $\begin{array}{l}\text { Was the level of FSMA Produce Safety Rule information provided in the curriculum } \\
\text { materials sufficient to guide produce growers in understanding and implementing the } \\
\text { regulatory requirements? }\end{array}$ & $87(683)$ & $13(101)$ & 0.5 \\
\hline $\begin{array}{l}\text { Was the curriculum well balanced in terms of providing GAPs guidance as well as FSMA } \\
\text { Produce Safety Rule requirements? }\end{array}$ & $89(670)$ & $11(83)$ & 0.071 \\
\hline Were the training protocol, PSA Lead Trainer review process, and course logistics clear? & $96(728)$ & $4(27)$ & 0.805 \\
\hline Did the course prepare you well to use this curriculum to train growers? & $95(731)$ & $5(36)$ & $0.046^{*}$ \\
\hline Is there additional assistance that the PSA can provide to facilitate a successful training? & $39(253)$ & $61(401)$ & $0.003^{*}$ \\
\hline
\end{tabular}

Most participants agreed that the level of FSMA PSR information provided was sufficient to guide growers in understanding and implementing requirements (87\% agreed) and that the curriculum was well balanced in terms of providing guidance for GAPs and PSR requirements ( $89 \%$ agreed). Initially, the amount of GAPs content interspersed within the regulatory requirements was identified as a concern by some collaborators. The PSA Steering and Executive Committees felt strongly that GAPs should be included in the curriculum so that PSA Grower Training attendees would understand the basic principles and science supporting the established regulatory provisions. Separate analysis of evaluation data from PSA Grower Training Courses revealed that over half (57\%) of participants had never previously attended a training on GAPs or produce safety, meaning that they relied on the PSA course to provide an introduction to produce safety basics and regulatory requirements $(n=10,703)$ (3). A basic principle of adult education is that learners need to understand the reasoning behind new information if they are to be motivated to learn the content (6). Adult education theory supports the inclusion of GAPs with regulatory requirements so that growers develop an understanding of why the regulatory requirements reduce food safety risks.
Most participants (95\%) reported that the course prepared them well to teach the curriculum to growers. This percentage significantly increased over time $(P=$ $0.046)$. Estimated marginal means analysis predicted that by 24 April 2017, 98\% of participants indicated that the PSA Train-the-Trainer Course prepared them well to teach the PSA Grower Training Course. This small but significant increase of $3 \%$ may be due to several factors: over time PSA Trainers of Trainers, who lead PSA Train-the-Trainer Courses, developed the ability to better answer participant questions on the spot, provide more resources, and connect participants with a support network to help them succeed once the training was completed. Of those attendees who indicated that they were not ready to teach the course, 18 individuals $(2.52 \%)$ intended to become PSA Lead Trainers. For these individuals, the additional resources developed and cotraining opportunities will be beneficial for assisting them to become ready to serve as a PSA Lead Trainer.

Participants commented that co-training and mentorship opportunities would be beneficial to their development as PSA Lead Trainers. As the training rolled out, a network of trainers and mentors was formed across the country, and the PSA continues to regularly connect new trainers with those willing to mentor. The PSA Regional Extension Associates prioritized their participation in PSA 


\section{TABLE 3. Materials developed to meet trainer needs}

\begin{tabular}{l|l} 
Trainer need & Addressed by PSA \\
\hline
\end{tabular}

Communications, technical assistance

\begin{tabular}{l|l}
\hline Email updates & $\begin{array}{l}\text { The PSA has a trainer listserv for disseminating updates on regulatory requirements, information about new } \\
\text { PSA training materials, and communicating changes in PSA policies and procedures. By the end of April 2017, } \\
\text { the trainer listserv contained } 960 \text { members. The PSA has two opt-in listservs: a general listserv for growers and } \\
\text { the general public to receive monthly newsletters }(>4,800 \text { members as of November 2019) and an educators' } \\
\text { listserv for PSA Trainers and produce safety educators who wish to receive information about advanced } \\
\text { training topics }(>400 \text { members as of November 2019). }\end{array}$ \\
\hline $\begin{array}{l}\text { List of PSA } \\
\text { Trainers, Lead } \\
\text { Trainers, and }\end{array}$ & $\begin{array}{l}\text { The PSA Trainer Directory was made publicly available in October } 2017 \text { and provides trainers with } \\
\text { opportunity to find other trainers, lead trainers, and trainers of trainers by country, state, language spoken, or } \\
\text { trainer type. }\end{array}$ \\
\hline Technical support & $\begin{array}{l}\text { The PSA is staffed with Extension Associates in each region available for technical assistance and a national } \\
\text { Spanish Language Extension Associate. Additional slides have been added to the Adult Education and Multiday } \\
\text { FDA Produce Safety Network, the FSMA Regional Centers tasked with FSMA outreach and education, the } \\
\text { Indigenous Food and Agriculture Initiative, and the Local Food Safety Collaborative. }\end{array}$ \\
\hline
\end{tabular}

Teaching and supplemental resources \begin{tabular}{l|l}
\hline $\begin{array}{l}\text { Required records, } \\
\text { fact sheet and } \\
\text { templates }\end{array}$ & $\begin{array}{l}\text { The publication Records Required by the FSMA Produce Safety Rule was developed and made publicly } \\
\text { available in March } 2017 \text { (20). This publication summarizes the PSR provisions requiring records and includes } \\
\text { template records to help growers meet PSR requirements. }\end{array}$
\end{tabular}

Several activities have been developed to increase experiential learning opportunities during the PSA Grower Training Course. The "Coliform Supplemental Activity" provides participants with an opportunity to better visualize the relationship between coliforms and various strains of E. coli. The activity "Is This Agricultural Hands-on Water?" provides visual examples of farm water use and generates discussion around the topic of the FDA activities $\quad$ definition of agricultural water. The "Name that Zone" activity includes visual examples of locations on the farm or in a packinghouse to generate discussion around cleaning and sanitizing. Additional, non-PSA resources, such as the use of Glo-Germ kits to illustrate handwashing or demonstrating how to properly measure sanitizer concentration using test strips, are also shared with trainers.

\begin{tabular}{l|l}
$\begin{array}{l}\text { Instructional } \\
\text { resources for } \\
\text { water testing and } \\
\text { sampling }\end{array}$ & $\begin{array}{l}\text { Supplemental slides for module 5 (Agricultural Water) have been developed to help trainers make growers } \\
\text { aware of changes and implementation delays related to the FSMA PSR, subpart E (agricultural water). } \\
\text { Several factsheets have been developed to help growers meet the PSR requirements in subpart E: "Geometric } \\
\text { Means, Statistical Threshold Values, and Microbial Die-Off Rates" (longhand calculations), "The Water } \\
\text { Analysis Method Requirement in the FSMA Produce Safety Rule," and "FSMA Produce Safety Rule Water } \\
\text { Requirements: Insights to Get You Organized!" }\end{array}$ \\
\hline Glossary & $\begin{array}{l}\text { Although a glossary was included with the materials at the rollout of the PSA Training Courses, PSA Trainers of } \\
\text { Trainers modified their teaching to spend ample time at the start of a training to ensure that participants were } \\
\text { aware of the many resources included within the binder. }\end{array}$
\end{tabular}

Trainer capacity building

\begin{tabular}{l|l}
\hline & $\begin{array}{l}\text { When PSA Trainers began delivering Grower Training Courses, many invited the PSA Extension Associates to } \\
\text { train with them. PSA Extension Associates also serve as a remote technical support team during trainings, and } \\
\text { they can be reached by trainers via phone, email, and text message. Priority was placed on collaborating with } \\
\text { organizations that are looking to develop trainer capacity through mentorship. The PSA team in collaboration } \\
\text { with the Southern Center for Food Safety Training, Outreach, and Technical Assistance developed a PSA } \\
\text { Advanced Training that was piloted in fall 2019. } \\
\text { mentorship }\end{array}$ \\
\hline
\end{tabular}




\section{TABLE 3. Materials developed to meet trainer needs [cont.] \\ \begin{tabular}{l|l} 
Trainer need & Addressed by PSA
\end{tabular}}

Other resources currently being developed

\begin{tabular}{|c|c|}
\hline $\begin{array}{l}\text { Teaching } \\
\text { examples, clicker } \\
\text { based discussion } \\
\text { questions, case } \\
\text { studies }\end{array}$ & $\begin{array}{l}\text { Teaching examples and case studies have been developed as part of a PSA Advanced Trainer curriculum. The } \\
\text { materials are not publicly available at this time, but further development of the PSA Advanced Trainer Course is } \\
\text { a focus of the PSA for } 2019 \text { and } 2020 \text {. }\end{array}$ \\
\hline $\begin{array}{l}\text { Farm food safety } \\
\text { plan template }\end{array}$ & $\begin{array}{l}\text { A Farm Food Safety Plan template including both FSMA PSR requirements and USDA harmonized GAP } \\
\text { requirements was released in } 2019 \text { in collaboration with the National Good Agricultural Practices Program. } \\
\text { The PSA has collaborated with the National Farmers Union, Local Food Safety Collaborative on the } \\
\text { development of an example food safety plan that covers only the requirements of the FSMA PSR. }\end{array}$ \\
\hline $\begin{array}{l}\text { Simplified or low } \\
\text { literacy training } \\
\text { materials }\end{array}$ & $\begin{array}{l}\text { Simplified training materials, such as photo-based activities, have been developed for certain modules. } \\
\text { Additional activities are being developed by produce safety educators. }\end{array}$ \\
\hline Online course & $\begin{array}{l}\text { An online PSA Grower Training Course launched in April 2020. The course is instructor led and includes the } \\
\text { PSA standardized curriculum slides and opportunities for further engagement. }\end{array}$ \\
\hline $\begin{array}{l}\text { Worker training } \\
\text { materials }\end{array}$ & $\begin{array}{l}\text { The National Good Agricultural Practices Program, in conjunction with the PSA, is producing a worker } \\
\text { training video that will include PSR requirements. }\end{array}$ \\
\hline $\begin{array}{l}\text { Exemptions from } \\
\text { the PSR and } \\
\text { compliance dates }\end{array}$ & $\begin{array}{l}\text { A FSMA PSR exemptions and exclusions PowerPoint presentation was developed when PSA Grower Training } \\
\text { evaluations revealed that growers were unsure of whether they were subject to the PSR. A "Clarification of } \\
\text { Compliance Dates" chart was developed in collaboration with the Southern Center for Food Safety Training, } \\
\text { Outreach, and Technical Assistance to assist both PSA trainers and growers in keeping track of compliance } \\
\text { dates for the PSR. }\end{array}$ \\
\hline
\end{tabular}

Grower Training Courses that provided opportunities to mentor new PSA Trainers.

This collaborative network was extended with the creation of a public directory of PSA Trainers and Lead Trainers (13).

Participants requested additional assistance from the PSA $39 \%$ of the time, but this percentage fell significantly over time $(P=0.003)$. Estimated marginal means analysis predicted that by 24 April 2017, only $29 \%$ of participants requested additional assistance through the evaluation. Participants requested that additional materials be referenced $35 \%$ of the time, and this percentage also fell significantly over time $(P=0.007)$. Estimated marginal means analysis predicted that by 24 April 2017, 26\% of participants indicated that additional materials should be referenced. The request for additional materials has decreased over time probably because resources are being consistently highlighted and developed. Specific to development of additional resources, the FSMA Regional Centers and other groups such as the Local Food Safety
Collaborative and the Native American Tribal Center for Food Safety Outreach, Education, Training and Technical Assistance have responded to cultural, regional, and commodity-specific educational needs. Many of these resources, including the materials developed by the PSA, are now publicly available on a national database hosted by the Northeast Center to Advance Food Safety (16). Working collaboratively has allowed the nationwide network of trainers and educators to access new resources and avoid duplication of efforts while prioritizing unique needs within their regions.

A detailed review of 246 comments left by participants from the first six courses in Arizona, California, Florida, Illinois, New York, and Washington was conducted to help identify key resource needs to be addressed by the PSA. The data revealed that participants have a strong desire for ongoing program development support and technical assistance from the PSA. The PSA has conducted an ongoing review of comments at the conclusion of each PSA Train-the-Trainer Course and has begun developing or 
collaborating on the development of many of the resources suggested by participants. The following categories of resources were requested in this small subset of initial training evaluations: teaching examples and case studies (23 requests), email updates (18 requests), a model food safety plan (17 requests), a photo library (15 requests), required records fact sheet and templates (12 requests), technical support (12 requests), hands-on activities (10 requests), simplified or low-literacy training materials (6 requests), a list of PSA Lead Trainers (4 requests), training mentorship (4 requests), water testing and sampling instructional resources (4 requests), an online PSA Grower Training Course (3 requests), a glossary of food safety terms used in the curricula ( 2 requests), and worker training materials ( 2 requests). Comments that were illegible, incomprehensible, or mentioned only once were omitted from this list. A summary of trainer material needs and how needs have been addressed by the PSA is given in Table 3. In addition to responding to immediate educational needs, the PSA provided timely adjustments to resources and communications during curriculum rollout to ensure the information was current. Some of the resources developed were in response to FDA policy updates and not necessarily from course attendee requests.

\section{Self-reported knowledge gain}

A significant difference in self-reported knowledge gain was found depending on the PSA Grower Training module $\left(\chi^{2}(7)=87.095, P<0.0001\right)$. Mean perceived knowledge gained was greatest for Agricultural Water: Postharvest Water (Module 5, part II) followed by Postharvest Handling and Sanitation (Module 6), Agricultural Water: Production Water (Module 5, part I), Soil Amendments (Module 3), Introduction to Produce Safety (Module
1), Worker Health, Hygiene, and Training (Module 2), Wildlife, Domesticated Animals, and Land Use (Module 4), and How to Develop a Farm Food Safety Plan (Module 7) (Table 4). Self-reported knowledge gained was greatest for modules in which the greatest number of additional resources have been developed. Priority was placed on developing resources to address immediate educational needs (such as from the FDA policy updates) and on modules containing the greatest complexity. The Postharvest Water and Postharvest Handling and Sanitation modules contain more technical information, which benefits from the support of additional educational resources.

A significant difference in self-reported knowledge gain was found among the PSA Train-the-Trainer additional modules (Principles of Adult Education, Multiday Training Options, and Training Logistics) $\left(\chi^{2}(2)=28.686, P<\right.$ $0.0001)$. Mean perceived knowledge gained was greatest for Training Logistics followed by Multi-day Training Options and Principles of Adult Education. The high number of Extension educators who have attended the PSA Train-theTrainer Course indicates that many attendees are likely to have previous training experience, but the experience may not be specific to produce safety. The Training Logistics module was new information, whereas trainers had likely had some experience with adult education principles and multiday training options in the past. The trainer competency areas, identified by the working groups, ensure that PSA Trainers and Lead Trainers would be prepared and qualified to teach the transdisciplinary course content.

\section{Participant training plans}

The majority of participants attending training during the first 8 months of the program intended to become PSA

\section{TABLE 4. Self-reported knowledge gained from PSA Grower Training modules}

\begin{tabular}{l|c} 
Module & Mean $\left(\boldsymbol{n = 7 2 4 ) ^ { a }}\right.$ \\
\hline 5, II. Agricultural water: postharvest water & $1.60 \mathrm{~A}$ \\
\hline 6. Postharvest handling and sanitation & $1.62 \mathrm{~A}$ \\
\hline 5, I. Agricultural water: production water & $1.63 \mathrm{AB}$ \\
\hline 3. Soil amendments & $1.68 \mathrm{AB}$ \\
\hline 1. Introduction to produce safety & $1.71 \mathrm{BC}$ \\
\hline 2. Worker health, hygiene, and training & $1.71 \mathrm{BC}$ \\
\hline 4. Wildlife, domesticated animals, and land use & $1.76 \mathrm{C}$ \\
\hline 7. How to develop a farm food safety plan & $1.79 \mathrm{C}$ \\
\hline
\end{tabular}

${ }^{a}$ Lower numbers indicate more knowledge gained. Means with different letters are significantly different $(P<0.002$, Wilcoxon signed ranks post hoc test with Bonferroni adjustment). 


\section{TABLE 5. Participant plans for training growers ( $=\mathbf{8 1 9}^{\mathrm{a}}$ )}

Do you intend to become a Lead Trainer?

\author{
Yes, \% (N) \\ $66 \%(492)$
}

\begin{abstract}
No, \% (N)
\end{abstract}
$34 \%$ (258)
Not sure, \% (N)

$\mathrm{N} / \mathrm{A}$

Do you plan to teach the course solo, build a team, or both to deliver the curriculum to growers? $\begin{array}{cc}\text { Teach solo, \% (N) } & \text { Teach as a team, \% (N) } \\ 3 \%(25) & 60 \%(456)\end{array}$
Both, \% (N)

$37 \%(274)$

If training as a team, do you feel that you will be able to find qualified people to join your team $?^{\text {b }}$

Yes, \% (N) $82 \%(595)$
No, \% (N)

$.3 \%(2)$
Not sure, \% (N)

$18 \%(129)$

Do you plan to offer the training in one day, or spread it out over multiple days?

One day, \% (N)

$30 \%(229)$

Yes, \% (N)

$42 \%(246)$
Multiple days, \% (N)

$21 \%(158)$

Not sure, $\%(\mathrm{~N})$

If you plan to host a multi-day training, do you plan to include a information $?^{c}$

${ }^{a}$ Every participant did not respond to every question.

'25 participants responded that they would be teaching solo, but also responded to this question. Those responses are not included in this analysis.

${ }^{c} 158$ participants responded that they would be teaching the training one day, but also responded to this question. Those responses are not included in this analysis.

Lead Trainers and to teach the course with a team (Table 5). Participants with a doctoral degree were most likely to report that they intended to become PSA Lead Trainers, and those with only a high school education were least likely to report that they intended to become PSA Lead Trainers $\left(\chi^{2}(7, N=723)=28.207, P<0.001\right)$. Consultants were most likely to report that they intended to become PSA Lead Trainers, and government employees and farm owners or operators were most likely to report that they did not intend to become PSA Lead Trainers $\left(\chi^{2}(5, N=725)\right.$ $=53.481, P<0.001)$. Participants 41 to 55 years of age $\left(\chi^{2}\right.$ $(4, N=717)=16.056, P<0.003)$ and those with at least 6 years of produce safety training experience $\left(\chi^{2}(5, N=703)\right.$ $=51.796, P<0.001)$ were most likely to report intending to become PSA Lead Trainers.

In the years since the launch of the PSA Train-the-Trainer program, many more courses have been held nationally and internationally. From 14 September 2016 to 27 June 2019, 1,912 individuals attended domestic Train-the-Trainer Courses, and 236 (12\%) have become PSA Lead Trainers. In 2017, the training curriculum was translated into Spanish and began to be used with international and domestic Spanish-speaking audiences. As of 27 June 2019, 760 individuals from outside the United States had attended a PSA Train-the-Trainer Course, and 107 (14\%) had become
PSA Lead Trainers. Of those that intended to teach the course with a team, most indicated that they would be able to find qualified people to join the training team (Table 4). Many participants were unsure whether they would be teaching the PSA Grower Training Course over multiple days and whether they would include food safety plan writing as part of the training.

Analysis of the evaluation results from the first 8 months after the rollout of the PSA Train-the-Trainer Course indicates that the training was well received by course participants. Course attendees felt that the balance between GAPs and FSMA PSR content within the curriculum and the amount of teaching notes was sufficient to helping growers understand the foundational principles of produce safety and how to use those principles to comply with the PSR. The interdisciplinary nature of produce safety requires that trainers have a broad background in production agriculture, food safety, and adult education to effectively provide education and outreach to fruit and vegetable growers. Although many participants came to the training with $<10$ years of experience in produce safety, the majority reported feeling prepared to teach PSA Grower Training standardized curriculum modules after attending the Train-the-Trainer Course. Engaging course attendees in the curriculum content through active discussion and 
peer-to-peer interactions helps to solidify the learning and identify trainer knowledge gaps.

The overarching goal of preparing participants to train growers using the PSA standardized training goes beyond simply attending the PSA Train-the-Trainer Course. Trainers will need continued support through mentoring opportunities to gain experience in teaching the PSA Grower Training Course and through technical assistance and timely updates. As the FSMA PSR evolves and regulatory policies and guidance are finalized and/or updated (e.g., Subpart E-Agricultural Water provisions), trainers will need a consistent and accurate conduit for receiving information to incorporate into PSA Grower Training Courses. The PSA has been responsive to these changes and utilizes several mechanisms to facilitate communication and allow trainers to connect with the information, resources, and technical assistance they may need. The development of additional activities and supplemental materials for trainers to utilize in PSA grower trainings will continue to be a critical priority to ensure that the curriculum is effective and engaging for a variety of stakeholders' educational needs. Working collaboratively with the FSMA Regional Centers and other industry partners will enable the sharing of ideas, tools, and resources without duplicating efforts. The field of produce safety is constantly evolving with new research findings, adoption of new farming practices, and key findings from outbreak investigations. In the future, trainers must have access to continuing education opportunities to share the most recent science, best practices, and regulatory updates. The PSA is responding to these needs by working collaboratively to develop advanced trainer workshops and supplemental modules on complex subject matter areas.

\section{ACKNOWLEDGMENTS}

The work of the PSA is supported by funding from the FDA and the USDA. Any opinions, findings, and conclusions expressed in this article are those of the authors and do not necessarily reflect the views of the FDA or the USDA. We thank the growers, industry members, regulators, and educators who contributed valuable thoughts in the development of this training program. The authors also thank Michele Humiston and Rob Way, who are integral members of the PSA team. Without their contributions to the trainer database, evaluation management, and graphic design, this work would not have been possible. In addition, we acknowledge the very important contribution of the PSA Trainers, who provided valuable feedback on their course evaluations. These contributions have resulted in changes to the curriculum and how it is presented and continues to help the PSA improve the standardized curriculum and the training program overall.

\section{REFERENCES}

1. Bennett, S. D., S. V. Sodha, T. L. Ayers, M. F. Lynch, L. H. Gould, and R. V. Tauxe. 2018. Produce-associated foodborne disease outbreaks, USA, 1998-2013. Epidemiol. Infect. 146:1397-1406.

2. Bloom, B. S. 1984. Taxonomy of educational objectives. Allyn and Bacon, Boston, MA.

3. Clements, D. P. 2019. Draft PSA GT course manuscript, 27 August (dmp274@cornell. edu). Available from the author at: woodskl@ aces.edu.

4. Hallyburton, A., and L. A. Evarts. 2014. Gender and online health information seeking: a five survey meta-analysis. $J$. Consum. Health Internet 18(2):128-142.

5. Interagency Food Safety Analytics Collaboration. 2018. Foodborne illness source attribution estimates for 2016 for Salmonella, Escherichia coli O157, Listeria monocytogenes, and Campylobacter using multi-year outbreak surveillance data, United States. Centers for Disease Control and Prevention, Atlanta.

6. Knowles, M. 1990. The adult learner: a neglected species, 4th ed. Gulf, Houston, TX.

7. Painter, J. A., R. M. Hoekstra, T. Ayers, R. V. Tauxe, C. R. Braden, F. J. Angulo, and P. M. Griffin. 2013. Attribution of foodborne illnesses, hospitalizations, and deaths to food commodities by using outbreak data, United States, 1998-2008. Emerg. Infect. Dis. 19:407-415.

8. Porter, S. R., and M. E. Whitcomb. 2005. Non-response in student surveys: the role of demographics, engagement and personality. Res. High Edu. 46(2):127-152.

9. Produce Safety Alliance. 2011. GAPs education and training materials conference. Proceedings. Available at: https:// producesafetyalliance.cornell.edu/sites/ producesafetyalliance.cornell.edu/files/ shared/documents/2011-PSA-Proceedings. pdf. Accessed 12 July 2019.

10. Produce Safety Alliance. 2012. Farmer focus group summary report. Available at: https:// producesafetyalliance.cornell.edu/sites/ producesafetyalliance.cornell.edu/files/ shared/documents/FocusGroupSummary. pdf. Accessed 12 July 2019.

11. Produce Safety Alliance. 2019. Project milestones. Available at: https:// producesafetyalliance.cornell.edu/alliance/ project-milestones/. Accessed 29 May 2019.

12. Produce Safety Alliance. 2019. Trainer and lead trainer process. Available at: https:// producesafetyalliance.cornell.edu/training/ train-trainer-course/psa-trainer-and-leadtrainer-process/. Accessed 29 May 2019.
13. Produce Safety Alliance. 2019. Trainer directory. Available at: http://resources. producesafetyalliance.cornell.edu/directory/. Accessed 31 May 2019.

14. Smith, G. 2008. Does gender influence online survey participation? A record-linkage analysis of university faculty online survey response behavior. Available at: https://files. eric.ed.gov/fulltext/ED501717.pdf. Accessed 16 January 2020.

15. Stull, K., K. R. Schneider, M. D. Danyluk, R. M. Goodrich Schneider, T. K. Chapin, A. Harder, A. Jackson-Davis, L. Kassama, R. Pacumbaba, E. Myles, A. Philyaw Perez, K. Gibson, C. Shoulders, K. Woods, C. Carter, J. Northcutt, K. Baker, K. Sarjeant, M. Harrison, J. Harrison, L. Dunn, P. Vijayakumar, M. Morgan, A. Adhikari, J. Silva, J. O’Banner, C. Gunter, B. Chapman, E. Rogers, C. Simmons, R. McReynolds, R. Jadeja, D. Jaroni, M. Ma, L. Feliciano Orellana, M. Plaza, J. Latorre, E. Negron, A. Wszelaki, M. Morgan, A. Fouladkhah, T. M. Taylor, A. Castillo, J. Masabni, B. Vaughan, F. Malekian, L. K. Strawn, A. Vallotton, R. Williams, R. Boyer, J. Eifert, and R. Balasubramanian. 2019. Southern Center for Food Safety Training, Outreach and Technical Assistance and Lead Regional Coordination Center, p. 65. In Proceedings of the Southern Region Integrated Produce 
Safety Conference, San Antonio, TX, 29 to 30 October 2019.

16. University of Vermont Extension. 2019. Northeast Center to Advance Food Safety. Available at: https://www.uvm.edu/ extension/necafs. Accessed 4 September 2019.

17. U.S. Food and Drug Administration. 1998. Guidance for industry: guide to minimize microbial food safety hazards for fresh fruits and vegetables. Available at: https://www. fda.gov/regulatory-information/search-fda- guidance-documents/guidance-industryguide-minimize-microbial-food-safetyhazards-fresh-fruits-and-vegetables. Accessed 8 May 2019.

18. U.S. Food and Drug Administration. 2013 Analysis of economic impacts: standards for the growing, harvesting, packing, and holding of produce for human consumption. Available at: https://www.fda.gov/media/94153/ download. Accessed 22 August 2019.
19. U.S. Food and Drug Administration. 2015. Standards for the growing, harvesting, packing, and holding of produce for human consumption. Final rule. Fed. Regist. 80:74353-74568.

20. Woods, K, D. Pahl, D. Stoeckel, B. Fick, G. Wall, and E. A. Bihn. 2018. Records required by the Produce Safety Rule (FSMA). Produce Safety Alliance, Cornell University, Ithaca, NY.

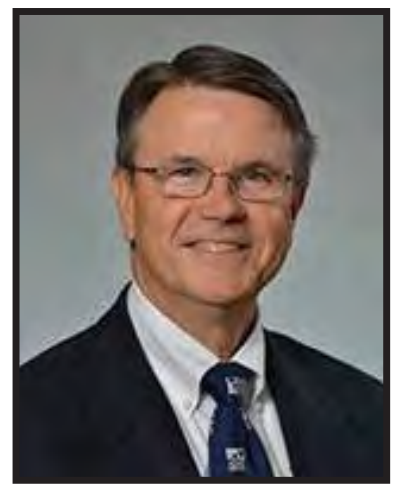

\section{In Memory Russell S. "Russ" Flowers Chapel Hill, North Carolina}

IAFP expresses our deepest sympathy to the family of Dr. Russell S. "Russ" Flowers, who passed away in September 2020 in Chapel Hill, North Carolina. Dr. Flowers joined IAFP in 1973 when it was known as the International Association of Milk, Food and Environmental Sanitarians (IAMFES). He received the Association's Harold Barnum Industry Award in 1999; both the IAFP Fellow Award and the Maurice Weber Laboratorian Award in 2010; and the Honorary Life Membership Award in 2014. Dr. Flowers presented the Ivan Parkin Lecture at IAFP 2008. He served on various IAFP organizing committees, providing his expertise to a wide range of scientific forums. With the IAFP Executive Board, he established the John H. Silliker Lecture in 2004.

Dr. Flowers retired in 2013 from Silliker Laboratories and Mérieux NutriSciences after a 34-year career, where he oversaw the expansion of Silliker from a small collection of testing facilities in North America to a global network with locations in 18 countries. He served as President, Chairman, and Chief Scientific Officer when the company was known as the SillikerGroup Corporation.

Dr. Flowers was a prolific researcher, author, and speaker in the field of food microbiology, with particular emphasis on the development and validation of rapid analytical methods and laboratory performance. He was the study director for the validation of the first Enzyme Immuno-Assay and Nucleic Acid Hybridization Assay approved by AOAC INTERNATIONAL and many subsequent studies that led to the industry-wide implementation of pathogen detection methods. In addition, Dr. Flowers chaired the Food Laboratory Accreditation Working Group, which developed specific accreditation criteria for food testing laboratories.

A past president of AOAC, Dr. Flowers chaired the association's Stakeholder Panel on Alternative Methods (ISPAM), a committee dedicated to harmonizing microbiological methods internationally. In 2013, AOAC recognized his lifetime of scientific achievements with the Harvey O. Wiley Award.

Dr. Flowers earned his B.S. and M.S. from North Carolina State University and his Ph.D. from the University of Illinois.

IAFP will always have sincere gratitude for Dr. Flowers' long-time contributions to the Association and to food safety. 